\title{
Thalamic or central pain states poststroke
}

\author{
Robert W Teasell MD FRCPC
}

\begin{abstract}
Central poststroke pain (CPSP) has received a significant
RW Teasell.

Thalamic or central pain states poststroke.

Pain Res Manage 1996;1(4):219-222.

Thalamic or central pain states are generally regarded as rare in stroke, occurring in fewer than $2 \%$ of patients. However, a recent study suggests that they may be more common, occurring in up to $8 \%$ of unselected stroke patients. Cerebrovascular lesions leading to central pain states do not necessarily involve the thalamus, but can occur following lower brainstem and suprathalamic lesions. Damage to the spinothalamocortical tract appears to be a prerequisite to the development of central poststroke pain (CPSP). Development of CPSP is likely related to denervation hyperexcitability of third or fourth order, thalamic or cortical neurons. Central pain is often described as a 'burning' sensation in association with an unpleasant association of tingling, pins and needles, or numbness. Spontaneous or evoked dysesthesia and allodynia/hyperalgesia are common. Central or thalamic pain is generally intractable to most therapeutic interventions. One case is presented to illustrate the typical clinical presentation of thalamic pain states and the difficulties in treating this pain.
\end{abstract}

Key Words: Central pain, Deafferentation, Stroke

amount of attention recently (1-9). One study reported that as many as $8 \%$ of all stroke patients had some form of CPSP. However, given the multitude of clinical impairments, disabilities or both suffered by stroke patients, it is not unusual for pain to be ignored or placed on the back burner (7). The original thalamic pain syndrome described by Dejerine and Roussy (10) characterized the thalamic pain syndrome as a thalamic lesion with slight hemiplegia, abnormal sensation, hemiataxia, hemiastoereognosia, intolerable pain and choreoatheroid movements (8). Thalamic or central pain states poststroke are generally characterized by burning, stabbing, knife-like pains and dysesthesia with allodynia and hyperalgesia frequently present.

\section{CASE PRESENTATION}

\section{Les états douloureux d'origines thalamique ou centrale à la suite d'un accident vasculaire cérébral}

RÉSUMÉ : En général, on considère que les états douloureux d'origines thalamique ou centrale sont rares dans les cas d'accident vasculaire cérébral (AVC) et qu'ils se produisent chez moins de $2 \%$ des patients. Pourtant, une étude récente laisse croire que ces douleurs seraient en fait plus courantes et qu'elles se produisent chez au moins $8 \%$ des patients non sélectionnés ayant subi un AVC. Les lésions cérébrovasculaires qui entraînent des états douloureux d'origine centrale n'impliquent pas nécessairement le thalamus mais peuvent aussi survenir à la suite de lésions touchant le tronc cérébral inférieur et la région supra-thalamique. Les lésions touchant le faisceau spinothalamocortical semblent être une condition préalable au développement de la douleur d'origine centrale suivant un AVC. Le développement de ce type de douleur est vraisemblablement lié à une hyperexcitabilité de dénervation de troisième ou quatrième ordre de neurones corticaux ou thalamiques. La douleur d'origine centrale est souvent décrite comme une sensation de «brûlure » associée à une sensation désagréable de picotements, de fourmillements ou d'engourdissement. Des dysesthésies spontanées ou déclenchées et des hyperalgies-allodynies sont fréquentes. La douleur thalamique ou centrale est en général réfractaire à la plupart des interventions thérapeutiques. On présente un cas qui illustre le tableau clinique typique des états douloureux d'origine thalamique ainsi que les difficultés à traiter ce type de douleur.
A 65-year-old woman with a history of diabetes suffered a rightsided stroke that led to a minimal left hemiparesis and sensory loss. Motor difficulties associated with stroke completely resolved within weeks. However, almost immediately after the stroke she developed an uncomfortable 'cold spot' in the palm of her left hand. It spread to involve her entire hand and remained in that location for several months, after which it progressed to involve the entire left side of her body where it remained unchanged. She complained of an ice-cold sensation, which she described as like putting her hand in dry ice. The pain was described as burning, constant and steady; it was most severe in her hand, next most severe in her rib cage, followed by her thigh and then her ankle and foot. It bothered her least of all in her face, where it was located primarily in her cheek and a small patch on her forehead. She also described frequent intermit-

Department of Physical Medicine and Rehabilitation, University of Western Ontario, London Health Sciences Centre, London, Ontario

Correspondence and reprints: Dr Robert Teasell, London Health Sciences Centre, University Campus, 339 Windermere Road, London, Ontario

N6A 5A5. Telephone 519-663-3235, fax 519-663-2941

Accepted for publication September 18, 1996 


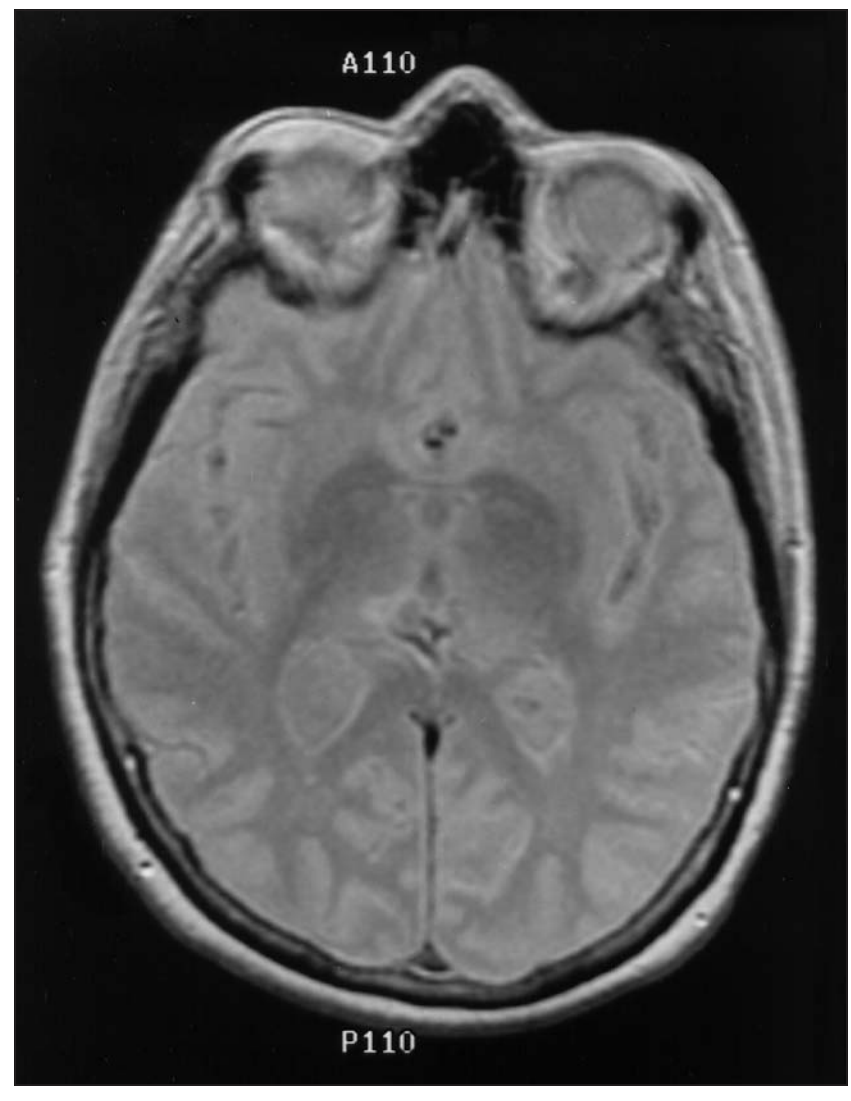

CASE REPORT tent stabbing pains; these came on spontaneously, lasting from seconds to minutes, and tended to be confined to the palm of her hand, left elbow and left rib cage. Light touch, such as clothing or even a light wind, caused discomfort along the entire left side of her body.

On examination there was some impairment of fine finger and fine toe movements on the left side, although strength was grossly normal and only minimally impaired. Over the entire left side of her body appreciation of light touch was altered. She found light touch uncomfortable over the left leg and arm, with the trunk less involved and the face least involved. Pin prick sensation was hyperpathic, tended to outlast the stimulus and had a burning, unpleasant quality to it; it involved the entire left side of the body with the exception of the cheek and forehead. Magnetic resonance imaging demonstrated a small infarct in the right upper midbrain and in the posterior and medial most aspect of the thalamus (Figure 1). Diagnosis was made of a thalamic pain syndrome. Treatment involved amitriptyline, carbamazepine and baclofen, as well as pain clinicinitiated intravenous xylocaine infusions. None of the treatments was successful, and she was subsequently treated with a mild narcotic with minimal pain relief. She continued to live at home independently.

\section{DISCUSSION}

\section{Pathophysiology}

CPSP is generally regarded as rare, occurring in fewer than $2 \%$ of cases (11-13), although a recent study reported an $8 \%$ incidence among unselected stroke patients with $5 \%$ reporting moderate to severe pain (8). Central pain resulting from a stroke is often referred to as 'thalamic pain' despite that, in many patients with CPSP, the cerebrovascular lesions do not involve the thalamus (4,14-18). Leijon et al (4) noted that central pain states occurred following lower brainstem, thalamic and suprathalamic cerebrovascular events. CPSP is invariably associated with a lesion involving the spinothalamocortical pathway with a disturbance in temperature and pain sensation (8).

The pathophysiology of CPSP states remains unknown. It is becoming increasing clear that damage to the spinothalamocortical pathway is a necessary prerequisite (1,7-10), although not all patients with damage to this pathway experience pain (8). CPSP is always associated with deficits in cold and warm stimuli and to pin prick sensation; these somatosensory functions are mediated by the spinothalamic tract $(1,2,9)$. However, other sensory deficits, such as touch, two-point discrimination and vibration sense, generally regarded as mediated by lemniscal pathways in the central nervous system, although often involved in CPSP states, may also be intact $(1,9)$. Vestergaard and colleagues (9) reported that lemniscal system lesions are not necessary for CPSP development.

Most, but not all, cases of CPSP are associated with hyperalgesia, allodynia or both. This paradoxical presence of a sensory deficit in combination with hyperalgesia in that part of the body deafferentated by the stroke lesion suggests a central sensitization of third and fourth order central nervous system neurons as a result of loss of spinothalamic (or thalamocortical) input (9). Hyperexcitability of thalamic or cortical neurons could then evoke the perception of pain. Vestergaard et al (9) noted that this hypothesis shares many features thought to be characteristics of other neuropathic pain syndromes, such as those associated with peripheral nerve lesions where spinal cord neurons that have lost their afferent input develop a central hyperexcitability (19-21).

\section{Clinical picture}

Central pain is often described as a 'burning' sensation in association with an unpleasant association of tingling, pins and needles, or numbness (13). It often is described in terms such as ripping, tearing, pressing, twisting, aching, pricking and lacerating $(1,4,8,13)$. Leijon et al (4), in their study of 23 patients with CPSP secondary to a known cerebrovascular lesion, noted little difference in the character of the pain in relation to the site of the lesion, with the exception that 'burning' pain was more commonly described with brainstem and suprathalamic lesions while 'lacerating' pain was seen more with the thalamic lesions. In their study of 16 patients with CPSP, Anderson and co-workers (8) noted no relation between size or location of the stroke and the presence of CPSP. CPSP pain is generally constant and often associated with spontaneous paroxysms of pain $(1,4,13)$. It also can be exacerbated by physical movement, emotional stress, loud noises or voices, changes in the weather, cold and light touch $(1,4,13)$.

Virtually all patients with CPSP report spontaneous or evoked parasthesia and/or dysesthesia $(4,8)$. Spontaneous dysesthesia occur in the majority of CPSP patients while almost all demonstrate some hypersensitivity to an external somatic stimuli (4). Hence, the spontaneous pain seen in central pain states may be accompanied by further unpleasant effects induced by somatosensory stimuli known as hyperalgesia, allodynia and dysesthesia. Dysesthesia are defined as unpleasant sensations, either spontaneous or evoked (8). Allodynia 
refers to an abnormally unpleasant somatosensory experience, often poorly localized, elucidated by normally non-nociceptive stimuli (8). Hyperalgesia is defined as an increased pain response to a normally painful stimulus (8). Initially hypersensitivity to sensory stimuli may make it difficult to differentiate CPSP from other pain entities, such as reflex sympathetic dystrophy, in the upper extremity. Anderson et al (8) noted that nine of 16 CPSP patients (56\%) reported allodynia to cold stimulation while another nine $(56 \%)$ reported allodynia to touch.

As discussed above, all patients with CPSP generally have some kind of sensory abnormality on the affected side (4). Decreased pin prick and threshold abnormalities to temperature detection are invariably present. However, touch, vibration and two-point discrimination are more variably involved. Allodynia and hyperalgesia have been discussed. Paralysis is not necessarily a feature of CPSP patients. Leijon et al (4) found that 14 of 27 patients (52\%) with CPSP had no paresis, ten $(37 \%)$ had moderate paresis and only four (15\%) had severe paresis.

CPSP does not necessarily begin immediately after the stroke. In their review of 16 CPSP patients, Andersen et al (8) noted that 10 $(63 \%)$ reported pain onset within one month of the stroke, three (19\%) within one to six months and three (19\%) after more than six months.

\section{Treatment}

Central pain is generally intractable to most therapeutic interventions. Narcotic and non-narcotic analgesics consistently fail to provide adequate pain relief (22). Tricyclic antidepressants have been shown to have a beneficial effect on central pain states $(23,24)$. In the mechanisms through analyses of the sensory abnormalities. Pain 1989;37:173-85.

2. Boivie J. Hyperalgesia and allodynia in patients with CNS lesions.In: Willis WD, ed. Hyperalgesia and Allodynia. New York: Raven Press, 1992:3633-73.

3. Bolvie J. Central pain. In: Wall PD, Melzack R, eds. Textbook of Pain. Edinburgh: Churchill-Livingstone, 1994:871-902.

4. Leijon G, Boivie J, Johansson I. Central post-stroke pain neurological symptoms and pain characteristics. Pain 1989;36:13-25.

5. Leijon G, Boivie J. Central post-stroke pain - a controlled study of amitriptyline and carbamazepine. Pain 1989;36:27-36.

6. Leijon G, Boivie J. Central post-stroke pain - the effect of high and low frequency TENS. Pain 1989;38:187-91.

7. Jensen TS, Lenz FA. Central post-stroke pain: a challenge for the scientist and the clinician. Pain 1995;61:161-4.

8. Andersen G, Vestergaard K, Ingeman-Nielsen M, Jensen TS. Incidence of central post-stroke pain. Pain 1995;61:187-93.

9. Vestergaard K, Nielsen J, Andersen G, Ingeman-Nielsen M, Arendt-Nielsen L, Jensen TS. Sensory abnormalities in consecutive, unselected patients with central post-stroke pain. Pain 1995;61:177-85.

10. Dejerine J, Roussy G. La syndrome thalamique. Rev Neurol 1906;14:521-32.

11. Pagni CA. Central pain due to spinal cord and brainstem damage.In: Wall PD, Melzack R, eds. Textbook of Pain. Edinburgh: Churchill-Livingstone, 1984:481-95.

12. Mucke L, Maciewicz R. Clinical management of neuropathic pain. Neurol Clin 1987;5:649-62.

13. Tasker RR. Pain resulting from central nervous system pathology (central pain). In: Bonica JJ, ed. The Management of Pain, vol 1, 2nd edn. Malvern: Lea \& Febiger, 1990:264-83.

14. Fields HL, Adams JE. Pain after cortical injury relieved by electrical stimulation of the internal capsule. Brain 1974;97:169-78.

15. Loh L, Nathan PW, Schott GD. Pain due to lesions of central nervous system removed by sympathetic block. BMJ 1981;282:1026-8.

16. Agnew DS, Shetter AG, Segall HD, Flom RA. Thalamic pain. In: Bonica J, Lindblom U, Iggo A, eds. Advances in Pain Research and Therapy, vol 5. New York: Raven Press, 1983:941-6. one controlled study, amitriptyline was shown to have some pain ameliorating effect on CPSP patients (5). Phenothiazines (chlorpromazine) (25) and anticonvulsants (phenytoin [26,27] and carbamazepine [5]) are only minimally effective in reducing pain (17). Apomorphine has been reported to be effective but associated with significant adverse effects and a tendency to lose its effectiveness over time (28). Transcutaneous electrical nerve stimulation has proved to be effective in some CPSP patients (6). Sympathetic blockade in the form of stellate ganglion and lumbar sympathetic blocks or local venous guanethedine blocks may provide some temporary pain relief (15). A variety of operative treatments have been tried for central pain states. These include neurosurgical brain lesions (29-32), brain stimulation (33-34) and even sterotaxic chemical hypophysectomy (35). Overall, neurosurgical ablative procedures have demonstrated a $25 \%$ effectiveness in permanently relieving central pain states but are associated with a significant risk of brain injury (36).

\section{CONCLUSIONS}

A case of central or thalamic poststroke pain is presented. These conditions may not be as rare as previously thought. Damage to the spinothalamocoritcal tract appears to be necessary, with denervation hyperexcitability of cortical or thalamic neurons the most popular hypothesis for the pain. Spontaneous or evoked dysesthesia and allodynia/hyperalgesia are very common. The majority of cases are intractable to treatment.

\section{REFERENCES}

1. Boivie J, Leijon G, Johansson I. Cental post-stroke pain - a study of

17. Bowsher D, Laheuerta J. Central pain in 22 patients: clinical features, somatosensory changes and CT scan findings. J Neurol 1985;232:237-97.

18. Garcin R, Lapresle J. Incoordination cerebrelleuse du membre inferieur par lesion localiseu dans la region intern du thalamus control-lateral. Rev Neurol (Paris) 1969;120:5.

19. Bennett GJ, Laird JMA. Central changes contributing to neuropathic hyperalgesia. In: Willis WD, ed. Hyperalgesia and Allodynia. New York: Raven Press, 1992:305-10.

20. Dubner R. Neuronal plasticity and pain following peripheral tissue inflammation or nerve injury. In: Bond MR, Charlton JE, Woolf CJ, eds. Pain Research and Clinical Management, vol 4. Amsterdam: Elsevier, 1991:263-76.

21. Wall PD. Neuropathic pain and injured nerve: central mechanisms. Br Med Bull 1991;47:631-43.

22. Nuzzo J, Warfield C. Thalamic pain syndrome. Hosp Pract 1985;20:32C-D,H-J

23. Koppel BS. Amitriptyline in the treatment of thalamic pain. South Med J 1986;79:759-61.

24. Tourian AY. Narcotic responsive 'thalamic' pain treatment with propanolol and tricyclic antidepressant. Pain 1987;Suppl 4:4S411.

25. Margolis LH, Gianascol AJ. Chlorpromazine in thalamic pain syndrome. Neurology 1956;6:302-4.

26. Mlandinich EK. Diphenylhydantoin in the Wallenberg syndrome. JAMA 1974;230:372-3.

27. Cantor FK. Phenytoin treatment of thalamic pain. BMJ 1972;4:590.

28. Miley DP, Abrams AA, Atkinson JH, Janowsky DS. Successful treatment of thalamic pain with apomorphine. Am J Psychiatry 1978;135:1230-2.

29. Davis RA, Stokes JW. Neurosurgical attempts to relieve thalamic pain. Surg Gynecol Obstet 1966;123:371-94.

30. Mark VH, Ervin FR, Yakolw PI. Correlation of pain relief sensory loss and anatomical lesion sites in pain patients treated by stereotactic thalamotomy. Trans Ann Neurol Assoc 1961;86:86-90.

31. Nashold BS, Wilson WP, Slaughter DG. Stereotaxic midbrain lesions 
for central dysesthesia and phantom pain: preliminary report.

J Neurosurg 1969;30:116-26.

32. White JC, Sweet WH. Pain and the Neurosurgeon. A Forty-Year Experience. Springfield: Charles C Thomas, 1969:386-406.

33. Meyerson BA. 'European' study on deep brain stimulation. Presented at the 3rd European Workshop on Electrical Neurostimulation.

Megeve, France, March 30-31, 1979.

34. Sweet WH. Intracerebral electrical stimulation for the relief of chronic pain. In: Youmans JR, ed. Neurological Surgery, 2nd edn. Philadelphia: WB Saunders, 1982:3739-48.

35. Levin AB, Ramirez LF, Katz J. The use of sterotaxic chemical hypophysectomy in the treatment of thalamic pain syndrome. J Neurosurg 1983;59:1002-6.

36. Pagni CA. Central pain and painful anaesthesia. Prog Neurol Surg $1977 ; 8: 132-257$ 


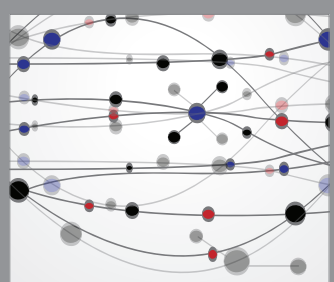

The Scientific World Journal
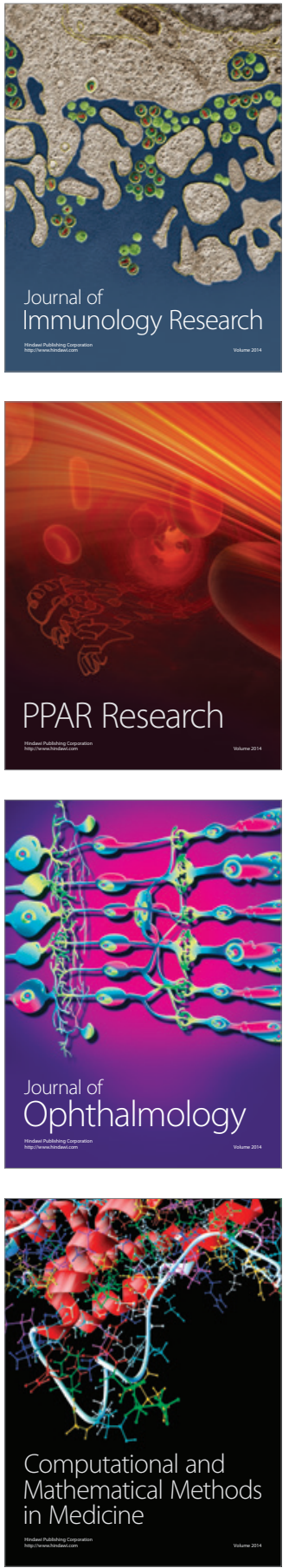

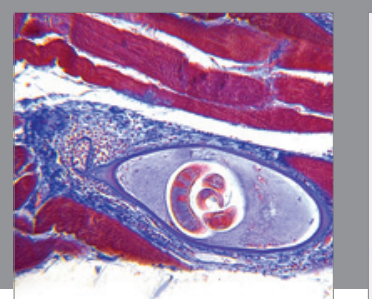

Gastroenterology Research and Practice

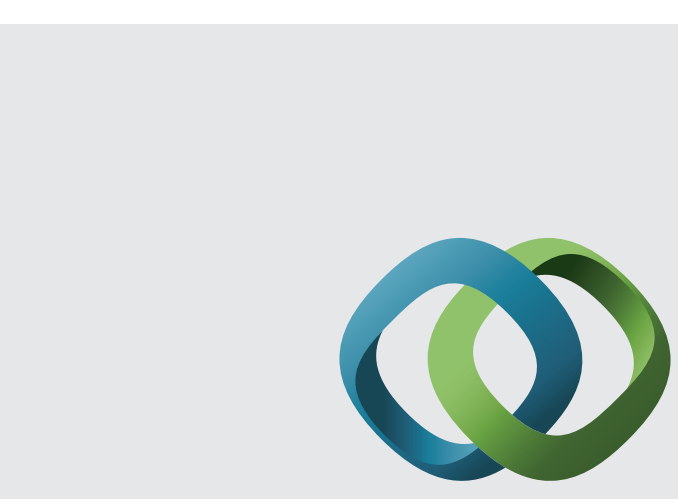

\section{Hindawi}

Submit your manuscripts at

http://www.hindawi.com
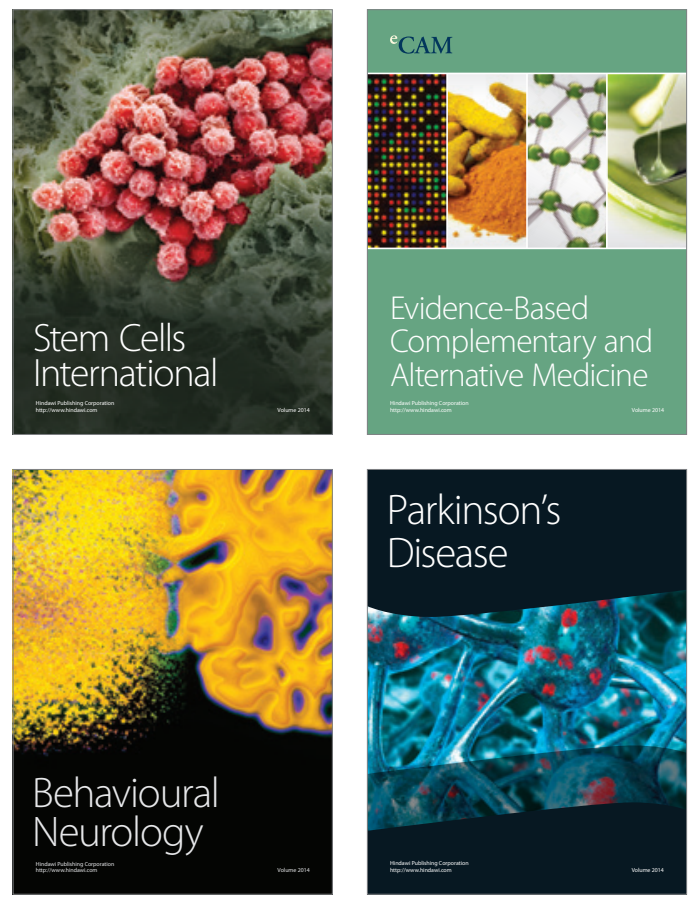
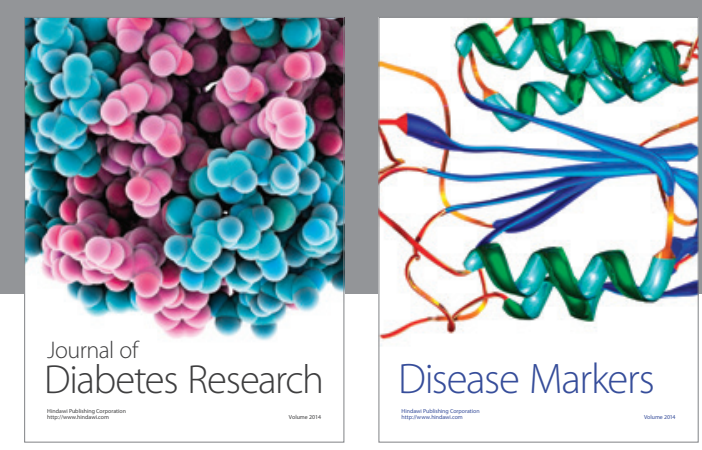

Disease Markers
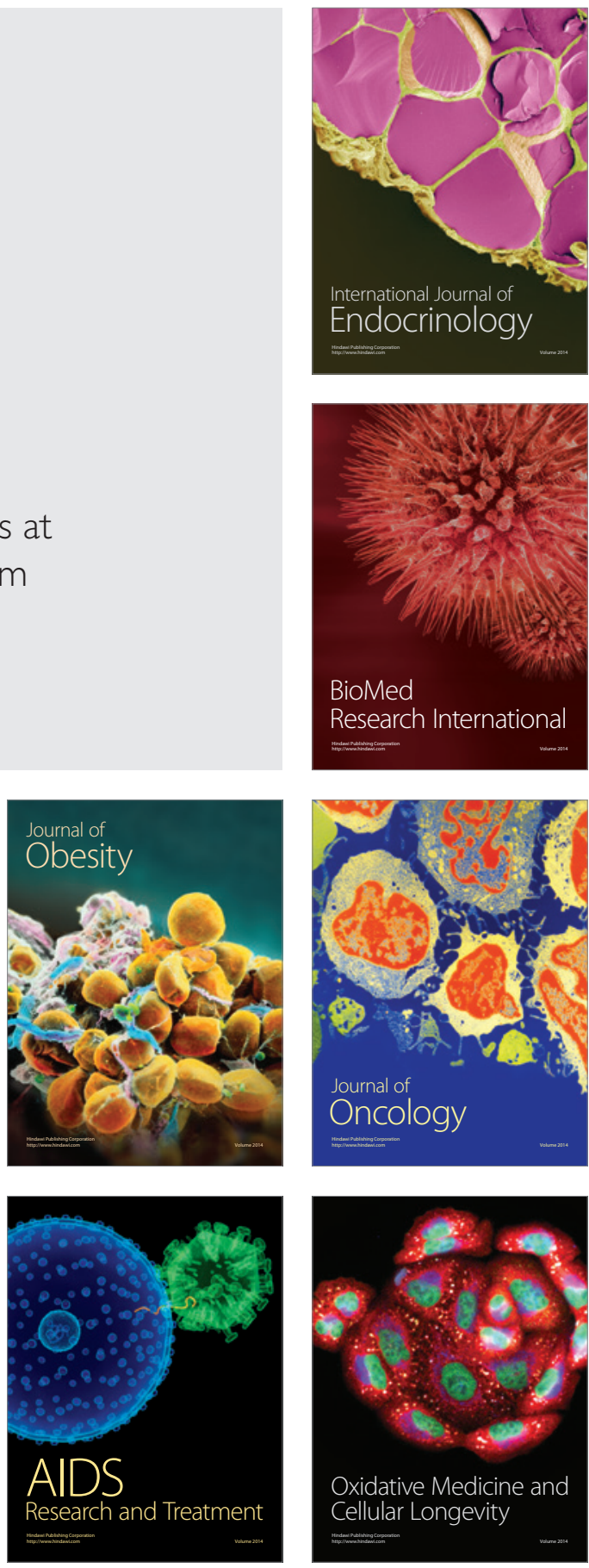